\title{
Patients' specific simulations of coronary fluxes in case of three-vessel disease
}

\author{
Mahmoud Maasrani ${ }^{1}$, Issam Abouliatim ${ }^{2,3}$, Majid Harmouche ${ }^{2,3}$, Jean-Philippe Verhoye ${ }^{2,3}$, \\ Hervé Corbineau ${ }^{2,3}$, Agnès Drochon ${ }^{4}$
}

${ }^{1}$ Faculty of Sciences, Lebanese University, Tripoli, Lebanon;

${ }^{2}$ Department of Thoracic and Cardiovascular Surgery, Rennes Hospital Center, Rennes, France;

${ }^{3}$ Research Unit INSERM U642, Rennes, France;

${ }^{4}$ University of Technology of Compiègne, Compiègne, France.

Email: agnes.drochon@utc.fr

Received 2 November 2010; revised 4 November 2010; accepted 8 November 2010.

\begin{abstract}
In this work, we propose a model of the coronary circulation based on hydraulic/electric analogy. This model aims to provide quantitative estimations of the distribution of flows and pressures across the coronary network for patients with stenoses of the left main coronary artery (LMCA), left anterior descending artery (LAD) and left circumflex branch (LCx), and chronic occlusion of the right coronary artery (RCA), undergoing off-pump coronary surgery. The results of the simulations are presented for 10 patients with various stenoses grades and collateral supply. For each patient, the four revascularization situations (no graft operating, pathological situation (0G); right graft only (1G), left grafts only (2G), complete revascularization ( $3 G)$ ) are considered. It is shown that: 1) the complete revascularization is fully justified for these patients because neither the right graft alone, nor the left grafts alone can ensure a sufficient perfusion improvement for the heart; 2) the capillary and collateral resistances (and the proportion between them) have a major impact on the flows and pressures everywhere in the network; 3 ) in the presence of the left grafts, the flows in the native stenosed arteries become low and this could promote the development of the native disease in these branches.
\end{abstract}

Keywords: Coronary Disease; Off-Pump Surgery; Patients' Specific Simulations; Lumped Parameter Model

\section{INTRODUCTION}

Bypass grafting is commonly performed to obtain myocardial reperfusion distal to critical coronary stenoses or thromboses. An accurate model of the coronary circula- tion would be helpful for predicting the effects of pathophysiological and pharmacological interventions, especially bypass grafts. Developing such a model is a complicated task due to the complexity of coronary hemodynamics, especially in pathological situations. Coronary artery diseases may induce the development of a coronary collateral circulation, which is generally estimated from a patient's angiogram. However, well developed collaterals are a risk factor for restenosis after bypass grafting due to competing hemodynamic forces. In this work, we study the case of severe coronary diseases: patients have stenoses of the left main coronary artery (LMCA), left anterior descending artery (LAD) and left circumflex branch (LCx), and chronic occlusion of the right coronary artery (RCA). In this clinical situation, the collateral circulation to the occluded artery is difficult to ascertain from preoperative measurements and it is debatable whether it is necessary to revascularize the right artery.

In a previously published paper [1], we proposed a model based on hydraulic/electric analogy that describes the coronary artery system mathematically. This model has been modified in order to include possible stenosis of the LMCA and to take into account variable stenosis coefficients on all left branches. In the present paper, we provide the detailed hemodynamic results for 10 patients with different stenoses severities. The simulations allow to know the pressures and flow rates in the stenosed native arteries, the collateral branches, the capillary areas, depending on the revascularization status (no grafts, right graft only, left grafts only, complete revascularization).

It is hoped that these computations will augment the surgeons professional experience in decision making process. 


\section{MATERIALS AND METHODS}

\subsection{Clinical Measurements for Each Patient}

Informed, signed consent was obtained from the patients before participating in the study.

The reductions in diameter and area of the stenosed arteries were estimated from angiographic observations, before surgery.

The off-pump coronary surgical procedure has been described previously [2]. The RCA is first revascularized via a saphenous vein graft. Two series of measurements are performed: $\mathrm{P}_{\mathrm{ao}}$ (aortic pressure), $\mathrm{P}_{\mathrm{v}}$ (central venous pressure), $\mathrm{P}_{\mathrm{w}}$ (pressure distal to the RCA occlusion), with the right graft clamped $(0 \mathrm{G})$; and $\mathrm{P}_{\mathrm{ao}}, \mathrm{P}_{\mathrm{v}}, \mathrm{Q}_{\mathrm{RCAg}}$ (flow rate in the RCA graft) with the right graft opened (1G). The left coronary arteries are then revascularized via the internal thoracic arteries. Two additional series of measurements are performed: $\mathrm{P}_{\mathrm{ao}}, \mathrm{P}_{\mathrm{v}}, \mathrm{P}_{\mathrm{w}}, \mathrm{Q}_{\mathrm{LADg}}$ and $\mathrm{Q}_{\mathrm{LCxg}}$ (flow rates in the LAD and LCx grafts) with the right graft clamped (2G); and $\mathrm{P}_{\mathrm{ao}}, \mathrm{P}_{\mathrm{v}}, \mathrm{Q}_{\mathrm{LADg}}, \mathrm{Q}_{\mathrm{LCxg}}$ and $\mathrm{Q}_{\mathrm{RCAg}}$ with the right graft opened $(3 \mathrm{G})$. Flow rates are measured with an ultrasonic transit time flowmeter (Butterfly Flowmeter 2001; Medi-Stim, Oslo, Norway), after hemodynamic stabilization.

\subsection{Biomechanical Model}

A lumped biomechanical model of this coronary network is proposed in Figure 1. In this model, the capillaries are represented by their hydraulic resistances $\left(\mathrm{R}_{\mathrm{LADc}}, \mathrm{R}_{\mathrm{LCXc}}\right.$, $\mathrm{R}_{\mathrm{RCAc}}$ are the resistances of the capillaries vascularized by the LAD, LCx and RCA arteries, respectively). The blood flow rates across the LAD, LCx and RCA capillaries are denoted by $\mathrm{Q}_{\mathrm{LADc}}, \mathrm{Q}_{\mathrm{LCX}}, \mathrm{Q}_{\mathrm{RCAc}}$ respectively. $\mathrm{Q}_{\text {col1 }}$ and $\mathrm{Q}_{\text {col4 }}$ are the collateral flow rates from LAD towards RCA (before and after LAD stenoses, respectively), $\mathrm{Q}_{\text {col2 }}$ and $\mathrm{Q}_{\text {col5 }}$ are the collateral flow rates from LCx (before and after LCx stenoses, respectively) and $\mathrm{Q}_{\mathrm{col} 3}$ is the collateral flow rate from the aorta towards the RCA.

Full resolution of the fluid mechanics equations in such a network is complicated. As suggested by several authors, prediction of flows and pressures can be facilitated by the use of an analog electrical model [3]

\subsection{The Electrical Model}

The electrical analog model corresponding to the coronary network of Figure $\mathbf{1}$ is shown in Figure 2. Each segment of the coronary artery can be simulated by an

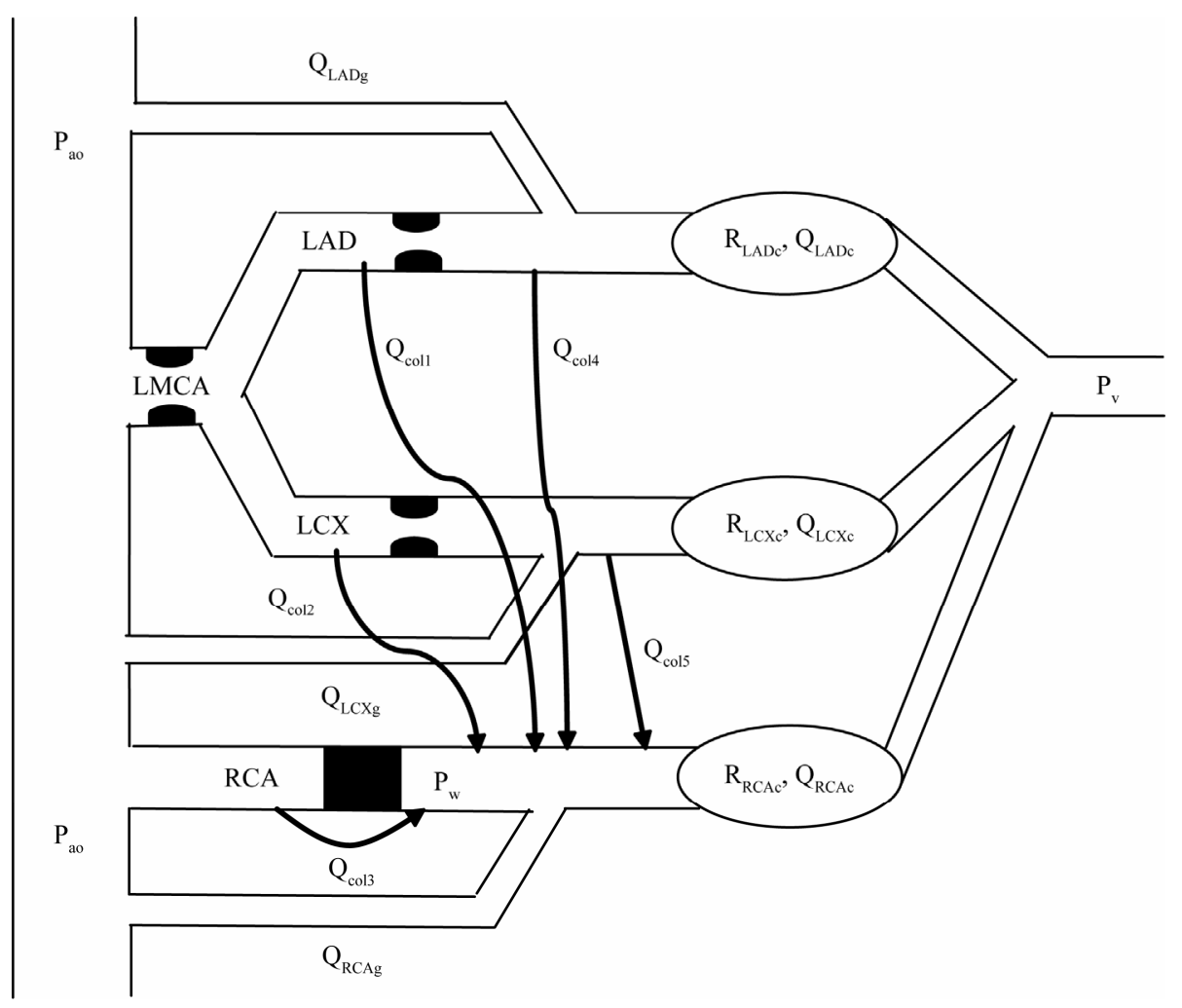

Figure 1. Simplified schematics of the coronary network in the case of patients with chronic occlusion of the right coronary artery (RCA), and stenoses on the left arteries (LMCA, LAD and LCx). The bypasses on the left arteries are performed with the internal mammary arteries (IMAG). The RCA is revascularized by saphenous vein graft (SVG). 


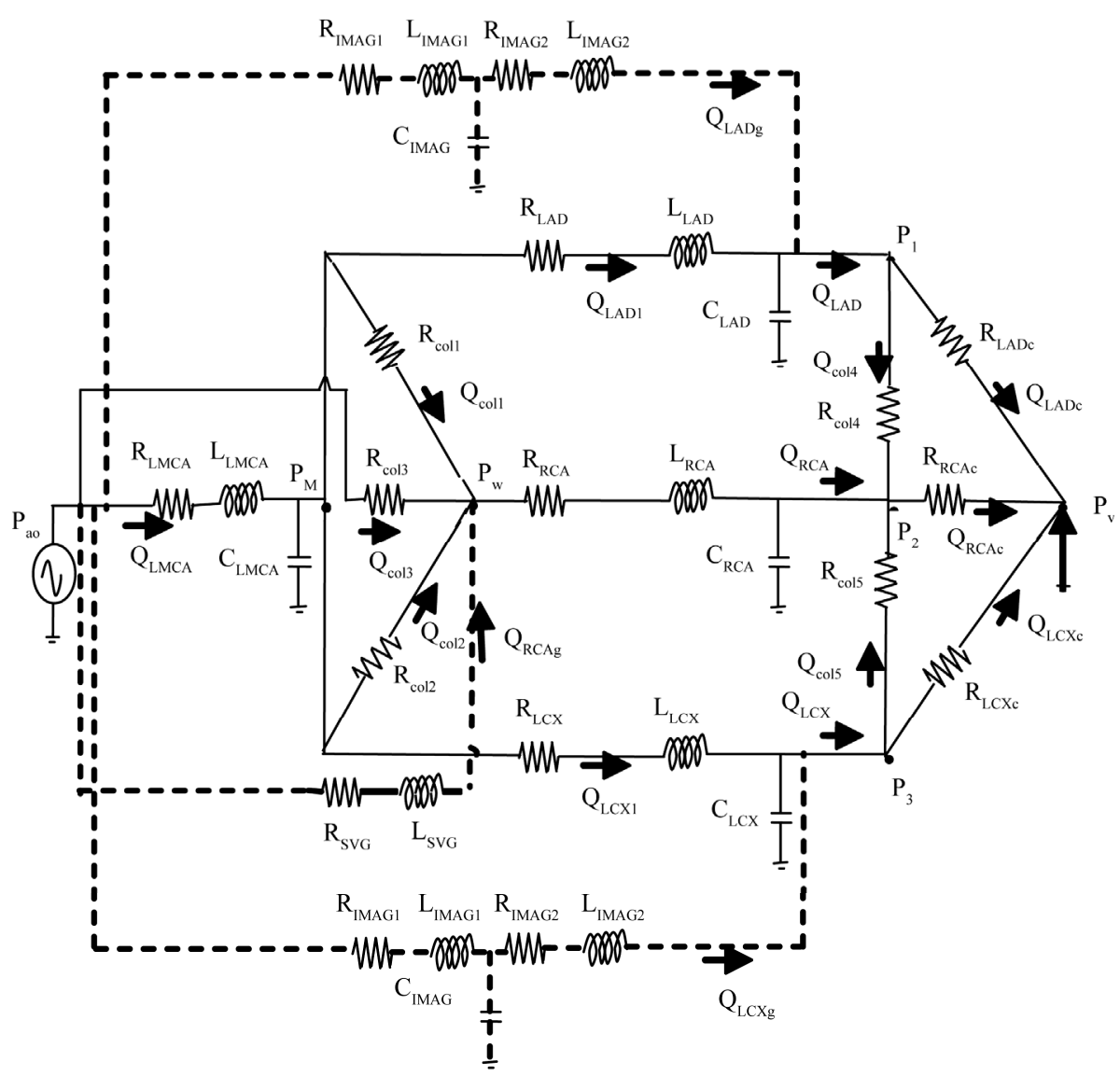

Figure 2. Analog electrical model for the network shown in Figure 1. The grafts are represented with dotted lines.

equivalent analog circuit model with resistance $\mathrm{R}$ (hydraulic resistance of the vessel), capacitance $\mathrm{C}$ (compliance of the vessel) and inductance $\mathrm{L}$ (inertia of the flowing blood). The LMCA is represented by $\mathrm{R}_{\mathrm{LMCA}}$, $\mathrm{C}_{\mathrm{LMCA}}$ and $\mathrm{L}_{\mathrm{LMCA}}$. The LAD is represented by $\mathrm{R}_{\mathrm{LAD}}$, $\mathrm{C}_{\mathrm{LAD}}$ and $\mathrm{L}_{\mathrm{LAD}}$. The $\mathrm{LCx}$ is represented by $\mathrm{R}_{\mathrm{LCX}}, \mathrm{C}_{\mathrm{LCX}}$ and $\mathrm{L}_{\mathrm{LCX}}$. The RCA is represented by $\mathrm{R}_{\mathrm{RCA}}, \mathrm{C}_{\mathrm{RCA}}$ and $\mathrm{L}_{\mathrm{RCA}}$. Our coronary artery system was modeled in the presence of bypasses. Pietrabissa et al. suggested some representation of internal mammary artery grafts (IMAG, used for left coronary artery bypasses) and saphenous vein grafts (SVG, used for the RCA) that are supported by physiological observations [4]. To take into account tapering, the IMAG is artificially divided into two segments of equal length $(70 \mathrm{~mm})$ but of different diameters (2.8 $\mathrm{mm}$ and $2 \mathrm{~mm}$, respectively); consequently, it is modeled by five elements: two resistances $\mathrm{R}_{\mathrm{IMAG}}, \mathrm{R}_{\mathrm{I}}$ MAG2; two coils $\mathrm{L}_{\mathrm{IMAG} 1}, \mathrm{~L}_{\mathrm{IMAG} 2}$; and a capacitor $\mathrm{C}_{\mathrm{IMAG}}$. SVG is modeled by two elements: a resistance $\mathrm{R}_{\mathrm{SVG}}$ and a coil $\mathrm{L}_{\mathrm{SVG}}$. The $\mathrm{SVG}$ model does not include an electric capacitance as experimental data confirm that when a vein is exposed to arterial pressure it loses its high compliance characteristics. The myocardial capillaries fed by the left and right coronary arteries are represented only by their resistances $R_{L A D c}, R_{L C X c}$ and $R_{R C A c}$. This approximation is convenient since the resistive effects are preponderant for small diameter vessels like capillaries [3]. For the same reason, the collateral vessels are also represented only by their resistances $R_{\text {coli }}, i=1-5$.

In this hydraulic/electric analogy, pressure and flow rate correspond to electrical voltage and current, respectively.

According to the network presented in Figure 2, the flow rate in the LAD artery, $\mathrm{Q}_{\mathrm{LAD}}$, is defined as the sum of the flow rate in the LAD graft, $Q_{\text {LADg, }}$ (if it exists), and of the flow rate in the stenosed native artery, $\mathrm{Q}_{\mathrm{LAD1}}$. The same notations are used for the LCx branch.

The sum of the right and left coronary flows is denoted $\mathrm{Q}_{\mathrm{t}}$ :

$$
Q_{t}=Q_{L A D}+Q_{L C x}+Q_{R C A}
$$

\subsection{Parameter Determination}

2.4.1. Vessel Resistance, Inductance and Compliance As suggested by Wang et al. [5] and Pietrabissa et al. [4], $\mathrm{R}, \mathrm{L}$ and $\mathrm{C}$ can be calculated for each vessel segment as 
follows:

$$
\begin{aligned}
R & =\frac{128 \mu l}{\pi D^{4}} \\
L & =\frac{4 \rho l}{\pi D^{2}} \\
C & =\frac{\pi D^{3} l}{4 E h}
\end{aligned}
$$

where $\mu=4 \times 10^{-3} \mathrm{~kg} \cdot \mathrm{m}^{-1} \cdot \mathrm{s}^{-1}$ is the blood viscosity; $\rho=$ $10^{3} \mathrm{~kg} \cdot \mathrm{m}^{-3}$ is the blood density; $\mathrm{E}=2 \times 10^{5} \mathrm{~Pa}$ is the Young modulus of the vessel; $1(\mathrm{~m})$ is the vessel length; $\mathrm{D}(\mathrm{m})$ is the vessel diameter and $\mathrm{h}(\mathrm{m})$ is the vessel wall thickness (estimated as: $\mathrm{h}=0.08 \mathrm{D}$ ).

Table 1 shows the values of R, L and C for the left and right coronary arteries and grafts. These values were provided by Pietrabissa et al. [4] except for the data for the RCA. In our study, the useful length of the RCA corresponds to the part distal to the thrombosis. This has been estimated as half of the LAD length and R, C and L for the RCA were deduced from those provided by Pietrabissa et al. for the LAD [4].

Left coronary stenoses were considered by varying the parameters of specific segments of the net as follows [5]:

$$
\begin{aligned}
& R=R_{0} \alpha^{-2} \\
& C=C_{0} \alpha^{3 / 2} \\
& L=L_{0} \alpha^{-1}
\end{aligned}
$$

where $\alpha=1-p, p$ is the percentage of area reduction of the stenosed vessel. $\mathrm{R}_{0}, \mathrm{C}_{0}$, and $\mathrm{L}_{0}$ are the values when $\mathrm{p}=$ 0 .

\subsubsection{Capillary Resistances}

These resistances $\left(R_{L A D c}, R_{L C X c}\right.$ and $\left.R_{R C A c}\right)$ are patientspecific. Their determination is performed using the experimental data of the case $(3 \mathrm{G})$ for each patient. The detailed calculations are given in [6].

Table 1. Values of resistance $\mathrm{R}$, inductance $\mathrm{L}$ and capacitance $\mathrm{C}$ for the vessels represented in the model.

\begin{tabular}{cccc}
\hline Vessel type & $\begin{array}{c}\text { Resistance } \\
(\mathrm{mmHg} . \mathrm{s} / \mathrm{ml})\end{array}$ & $\begin{array}{c}\text { Inductance } \\
\left(\mathrm{mmHg} . \mathrm{s}^{2} / \mathrm{ml}\right)\end{array}$ & $\begin{array}{c}\text { Capacitance } \\
(\mathrm{ml} / \mathrm{mmHg})\end{array}$ \\
\hline LMCA & 0.1 & 0.02 & 0.002 \\
LAD & 0.5 & 0.03 & 0.0015 \\
LCx & 0.3 & 0.02 & 0.0011 \\
RCA & 0.3 & 0.02 & 0.0008 \\
IMAGI & 1.4 & 0.08 & 0.0054 \\
IMAGII & 5.3 & 0.17 & \\
SVG & 0.2 & 0.04 & \\
\hline
\end{tabular}

\subsubsection{Collateral Resistances}

Due to the difficulty of determining the exact characteristics of the collateral pathways, it was assumed that all the collateral resistances are the same [1]:

$$
R_{\text {col } 1}=R_{\text {col2 }}=R_{\text {col3 }}=R_{\text {col } 4}=R_{\text {col } 5}=R_{\text {col }}
$$

This resistance is also specific to each patient.

In the case of RCA occlusion and three vessel disease, the value of $R_{\text {col }}$ is strongly related to the value of pressure $P_{w}$. Thus, the $P_{w}$ value measured in case $(2 G)$ is used as a convergence criterion to numerically determine the convenient value of $\mathrm{R}_{\mathrm{col}}$ for the patient. The numerical simulations are performed using the Matlab Simulink program. The value of $R_{\text {col }}$ is changed until the calculated $\mathrm{P}_{\mathrm{w}}$ value converges towards the clinically measured one.

\subsection{Flow Rate and Pressure Simulations}

\subsubsection{Aortic Pressure}

The input of the model is the aortic pressure wave, $\mathrm{P}_{\mathrm{ao}}(\mathrm{t})$, measured for each patient and each situation $(0 \mathrm{G}, 1 \mathrm{G}, 2 \mathrm{G}$, 3G).

\subsubsection{Matlab Simulations}

Once the model parameters are determined, flow and pressure predictions can be performed in any branch of the model and for all surgical cases. The calculated flows and pressures are time-dependent, but we focus on average cardiac cycle values. This is consistent with the fact that the collected clinical data are also average cardiac cycle values.

The influence of ventricular contraction upon coronary vascular bed resistance and compliance is not taken into account in our simulations. The impact of this assumption is probably less important in the case of our study than it would be for healthy patients. Wang et al. [5] have indeed shown that when severe stenoses exist, the significance of the collapse effect of intramural arteries due to myocardial contraction is reduced.

\section{RESULTS}

\subsection{Stenoses Severity}

The percentages of area reduction of the stenosed vessels for each patient are given in Table 2. For all patients, the RCA is totally occluded. Patient 7 has no stenosis on LAD; Patient 9 and 10 have no stenosis on LCx. Patients 1, 4 and 5 have moderate lesions on LMCA. Patient 1 has a very severe lesion on LAD.

\subsection{Capillary and Collateral Resistances}

The values of the capillary and collateral resistances for each patient are presented in Table 3. Despite the fact that the description of the coronary network presented in 
Table 2. Percentage of area reduction of the stenosed vessels for each patient.

\begin{tabular}{cccc}
\hline Patient & \% area LMCA & \% area LAD & \% area LCx \\
\hline 1 & 26 & 99 & 90 \\
2 & 46 & 89 & 95 \\
3 & 91.6 & 84.8 & 95.6 \\
4 & 19 & 86 & 97 \\
5 & 20 & 88 & 92 \\
6 & 85 & 94 & 82 \\
7 & 80 & 0 & 85 \\
8 & 87 & 70 & 90 \\
9 & 83 & 78 & 0 \\
10 & 75 & 93 & 0 \\
\hline
\end{tabular}

Table 3. Values of the capillary resistances, $\mathrm{R}_{\mathrm{LADc}}, \mathrm{R}_{\mathrm{LCxc}}$, $\mathrm{R}_{\mathrm{RCAc}}$, and collateral resistances, $\mathrm{R}_{\text {col }}$, for the patients considered in the study. All these values are given in $\mathrm{mmHg}$. $\mathrm{s} / \mathrm{ml}$.

\begin{tabular}{ccccc}
\hline Patient & $\mathrm{R}_{\mathrm{LADc}}$ & $\mathrm{R}_{\mathrm{LCxc}}$ & $\mathrm{R}_{\mathrm{RCAc}}$ & $\mathrm{R}_{\mathrm{col}}$ \\
\hline 1 & 83.3 & 207.9 & 54.1 & 160 \\
2 & 174.6 & 210.9 & 96.9 & 430 \\
3 & 213 & 94.2 & 62.8 & 350 \\
4 & 47.5 & 119.1 & 147.2 & 565 \\
5 & 175.3 & 68.7 & 56.1 & 205 \\
6 & 240.4 & 135.5 & 117.6 & 1055 \\
7 & 50.2 & 118.4 & 76 & 650 \\
8 & 77.6 & 196 & 347.6 & 970 \\
9 & 374.8 & 33.7 & 80.7 & 420 \\
10 & 155.9 & 62.1 & 213.8 & 405 \\
Mean $\pm \sigma$ & $159.3 \pm 96.6$ & $124.6 \pm 59.9$ & $125.3 \pm 87.6$ & $521 \pm 282.3$ \\
\hline
\end{tabular}

this paper is more precise than that presented in the previous paper [1], the mean values obtained for these 10 patients are in the same range than those previously published. As discussed in [1], these values are in good agreement with literature data. Important values of $R_{c o l}$ indicate that the collateral network is not very developed or not functional. The values of resistances presented in Table 3 are affected by a great variability. This finding supports the motivation of our work: the necessity to provide patients' specific simulations.

\subsection{Flows in LAD Branch and in LCx Branch}

In the following, all the quantities are calculated values, except when indicated with the notation "Cli" (used to denote measured clinical values).

The values of the flow rates in the native stenosed $\mathrm{LAD}\left(\mathrm{Q}_{\mathrm{LAD1}}\right)$, in the $\mathrm{LAD}$ graft $\left(\mathrm{Q}_{\mathrm{LADg}}\right)$ and the total flow rate in the $\mathrm{LAD}$ branch $\left(\mathrm{Q}_{\mathrm{LAD}}\right)$ are given in Table 4.

The same type of values, for the LCx branch, are given in Table 5.

One can notice that the flow rates in the native stenosed artery, $\mathrm{Q}_{\mathrm{LAD1}}$ or $\mathrm{Q}_{\mathrm{LCx} 1}$, is only slightly affected by the presence of the right graft (mean value of $\mathrm{Q}_{\mathrm{LAD} 1}$ in the case $(1 \mathrm{G})=25.3 \pm 24.2$ and in the case $(0 \mathrm{G})=$ $28.4 \pm 24.1$; mean value of $\mathrm{Q}_{\mathrm{LCx} 1}$ in the case $(1 \mathrm{G})=28.0 \pm$ 23.4 and in the case $(0 G)=31.3 \pm 23.5)$. This slight decrease is due to the fact that, in the presence of the right graft, the pressure drop across the LAD or LCx stenosis is slightly modified (because the pressure gradients across the collaterals are modified).

On the contrary, there is an important decrease of $\mathrm{Q}_{\mathrm{LAD} 1}$ and $\mathrm{Q}_{\mathrm{LCx} 1}$ in the presence of the left grafts (mean value of $\mathrm{Q}_{\mathrm{LAD} 1}$ in the case $(2 \mathrm{G})=7.9 \pm 17.2$, in the case $(3 \mathrm{G})=7.4 \pm 15.7$ and in the case $(0 \mathrm{G})=28.4 \pm 24.1$; mean value of $\mathrm{Q}_{\mathrm{LCx} 1}$ in the case $(2 \mathrm{G})=11.4 \pm 18.8$, in the case $(3 \mathrm{G})=12.5 \pm 22.3$ and in the case $(0 \mathrm{G})=31.3 \pm$ 23.5). This decrease is less important for Patient 7 (no stenosis on LAD) and for Patient 9 and 10 (no stenosis on LCx). When the LAD graft or LCx graft are present, the pressure drops across the LAD or LCx stenosis are reduced and since the hydraulic resistances of these stenosed arteries remain the same, the flow rate drops. Some sort of flow compensation appears between the graft and the native artery, especially if the native artery is not too severely obstructed (for example, this remark does not apply for the Patient 1, whose LAD branch is almost totally obstructed). Overall, the perfusion of the LAD territory $\left(\mathrm{Q}_{\mathrm{LAD}}\right)$ or of the $\mathrm{LCx}$ territory $\left(\mathrm{Q}_{\mathrm{LCx}}\right)$ is improved in the presence of the left grafts, but this improvement remains moderate (lower than $10 \mathrm{ml} / \mathrm{min}$ ). This finding is important because it means that the graft could thus promote progression of native disease. It is hoped that these results will bring some new arguments to the controversy that exists regarding the competitive flows between the native stenosed artery and the graft [7-11].

For Patient 9, a negative $\mathrm{Q}_{\mathrm{LAD} 1}$ flow is obtained in the presence of the left grafts (cases $(2 \mathrm{G})$ and $(3 \mathrm{G})$ ).

For this patient, the LAD capillary resistance, $\mathrm{R}_{\mathrm{LAD} c}$, is quite high when compared to $\mathrm{R}_{\mathrm{LCxc}}$, and is of the same order as $\mathrm{R}_{\text {col }}$. Besides, the LAD stenosis is not too severe; so that the blood brought by the LAD graft will flow preferentially in the native LAD branch rather than through $\mathrm{R}_{\mathrm{LADc}}$ or $\mathrm{R}_{\mathrm{col} 4}$. The same explanation prevails for Patient 3, but this patient has more severe obstructions of 
Table 4. Values of the flow rates $(\mathrm{ml} / \mathrm{min})$ in the native stenosed $L A D\left(Q_{L A D 1}\right)$, in the LAD graft $\left(Q_{L A D g}\right)$, and total flow rate in the $\mathrm{LAD}$ branch $\left(\mathrm{Q}_{\mathrm{LAD}}\right)$. These values are given for each patient, in the four different revascularization situations $(0 \mathrm{G}$, $1 \mathrm{G}, 2 \mathrm{G}, 3 \mathrm{G})$.

\begin{tabular}{|c|c|c|c|c|}
\hline Patient & $\mathrm{Q}_{\mathrm{LAD} 1}(0 \mathrm{G})$ & $\mathrm{Q}_{\mathrm{LAD} 1}(1 \mathrm{G})$ & $\mathrm{Q}_{\mathrm{LAD} 1}(2 \mathrm{G})$ & $\mathrm{Q}_{\mathrm{LAD} 1}(3 \mathrm{G})$ \\
\hline 1 & 0.1 & 0.1 & 0 & 0 \\
\hline 2 & 23.6 & 19.7 & 3.6 & 3.3 \\
\hline 3 & 20.7 & 15.6 & -1.7 & 2.5 \\
\hline 4 & 56.2 & 56.2 & 15 & 15.7 \\
\hline 5 & 25.9 & 18 & 4.3 & 3.5 \\
\hline 6 & 11.6 & 8.3 & 0.3 & 0.3 \\
\hline 7 & 77.5 & 73.2 & 52.1 & 46.1 \\
\hline 8 & 45.7 & 44.6 & 14.9 & 14.5 \\
\hline 9 & 10.4 & 6.5 & -10.2 & -12.2 \\
\hline 10 & 12.1 & 10.7 & 0.5 & 0.5 \\
\hline Mean $\pm \sigma$ & $28.4 \pm 24.1$ & $25.3 \pm 24.2$ & $7.9 \pm 17.2$ & $7.4 \pm 15.7$ \\
\hline Patient & $\mathrm{Q}_{\mathrm{LADg}} \mathrm{Cli}(2 \mathrm{G})$ & $\mathrm{Q}_{\text {LADg }}(2 \mathrm{G})$ & $\mathrm{Q}_{\mathrm{LADg}} \mathrm{Cli}(3 \mathrm{G})$ & $\mathrm{Q}_{\text {LADg }}(3 \mathrm{G})$ \\
\hline 1 & 34 & 39.6 & 40 & 38.9 \\
\hline 2 & 23 & 24 & 21 & 21.1 \\
\hline 3 & 22 & 28.5 & 19 & 19 \\
\hline 4 & 59 & 54.3 & 57 & 56.8 \\
\hline 5 & 24 & 22.3 & 18 & 18.3 \\
\hline 6 & 11 & 17.9 & 14 & 14.3 \\
\hline 7 & 28 & 36.3 & 28 & 28.2 \\
\hline 8 & 38 & 31.8 & 28 & 28.1 \\
\hline 9 & 24 & 23.1 & 23 & 22.9 \\
\hline 10 & 20 & 21.7 & 18 & 18 \\
\hline Mean $\pm \sigma$ & $28.3 \pm 13.1$ & $30.0 \pm 11.0$ & $26.6 \pm 13.0$ & $26.6 \pm 12.8$ \\
\hline Patient & $\mathrm{Q}_{\mathrm{LAD}}(0 \mathrm{G})$ & $\mathrm{Q}_{\mathrm{LAD}}(1 \mathrm{G})$ & $\mathrm{Q}_{\mathrm{LAD}}(2 \mathrm{G})$ & $\mathrm{Q}_{\mathrm{LAD}}(3 \mathrm{G})$ \\
\hline 1 & 0.1 & 0.1 & 39.3 & 38.6 \\
\hline 2 & 23.6 & 19.7 & 27.1 & 24 \\
\hline 3 & 20.7 & 15.6 & 26.1 & 21.1 \\
\hline 4 & 56.2 & 56.2 & 69.1 & 72.2 \\
\hline 5 & 25.9 & 18 & 25.8 & 21.1 \\
\hline 6 & 11.6 & 8.3 & 17.8 & 14.3 \\
\hline 7 & 77.5 & 73.2 & 87.8 & 73.8 \\
\hline 8 & 45.7 & 44.6 & 46.5 & 42.3 \\
\hline 9 & 10.4 & 6.5 & 12.5 & 10.3 \\
\hline 10 & 12.1 & 10.7 & 21.9 & 18.2 \\
\hline Mean $\pm \sigma$ & $28.4 \pm 24.1$ & $25.3 \pm 24.2$ & $37.4 \pm 24.1$ & $33.6 \pm 23.0$ \\
\hline
\end{tabular}

Table 5. Values of the flow rates $(\mathrm{ml} / \mathrm{min})$ in the native

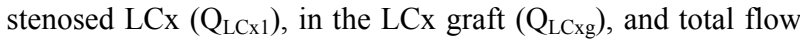
rate in the $\mathrm{LCx}$ branch $\left(\mathrm{Q}_{\mathrm{LCx}}\right)$. These values are given for each patient, in the four different revascularization situations.

\begin{tabular}{ccccc}
\hline Patient & $\mathrm{Q}_{\text {LCx1 }}(0 \mathrm{G})$ & $\mathrm{Q}_{\mathrm{LCx} 1}(1 \mathrm{G})$ & $\mathrm{Q}_{\mathrm{LC} \times 1}(2 \mathrm{G})$ & $\mathrm{Q}_{\mathrm{LCx} 1}(3 \mathrm{G})$ \\
\hline 1 & 19.9 & 13.7 & 3.5 & 2.8 \\
2 & 15.4 & 12.4 & 1.3 & 1.2 \\
3 & 15.1 & 13.9 & 0.7 & 1.5 \\
4 & 8 & 7.4 & 0.6 & 0.5 \\
5 & 37.5 & 31.8 & 6.3 & 6.2 \\
6 & 29.8 & 22.6 & 7.2 & 7.3 \\
7 & 31.2 & 27.5 & 2.6 & 2.3 \\
8 & 17.3 & 15.9 & 0 & 0.2 \\
9 & 87.1 & 84.8 & 54.7 & 69.2 \\
10 & 51.9 & 49.5 & 37.1 & 33.9
\end{tabular}

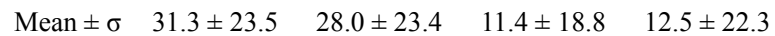

Patient $\quad$ QLCxg $_{\text {LCli }}(2 \mathrm{G}) \quad \mathrm{Q}_{\mathrm{LCxg}}(2 \mathrm{G}) \quad \mathrm{Q}_{\mathrm{LCxg}} \mathrm{Cli}(3 \mathrm{G}) \quad \mathrm{Q}_{\mathrm{LCxg}}(3 \mathrm{G})$

\begin{tabular}{|c|c|c|c|c|}
\hline 1 & 27 & 17.6 & 14 & 13.9 \\
\hline 2 & 32 & 22.4 & 19 & 19.2 \\
\hline 3 & 48 & 49.2 & 45 & 44.7 \\
\hline 4 & 40 & 30.2 & 30 & 30.1 \\
\hline 5 & 56 & 46.6 & 46 & 45.6 \\
\hline 6 & 12 & 22.6 & 18 & 18.1 \\
\hline 7 & 43 & 37.5 & 29 & 29.2 \\
\hline 8 & 16 & 19.9 & 17 & 17.2 \\
\hline 9 & 60 & 41.1 & 45 & 44.6 \\
\hline 10 & 7 & 15.9 & 13 & 13 \\
\hline Mean $\pm \sigma$ & $34.1 \pm 18.4$ & $30.3 \pm 12.4$ & $27.6 \pm 13.4$ & $27.6 \pm 13.3$ \\
\hline Patient & $\mathrm{Q}_{\mathrm{LCX}}(0 \mathrm{G})$ & $\mathrm{Q}_{\mathrm{LCx}}(1 \mathrm{G})$ & $\mathrm{Q}_{\mathrm{LCx}}(2 \mathrm{G})$ & $\mathrm{Q}_{\mathrm{LCx}}(3 \mathrm{G})$ \\
\hline 1 & 19.9 & 13.7 & 20.9 & 16.5 \\
\hline 2 & 15.4 & 12.4 & 23.2 & 19.9 \\
\hline 3 & 15.1 & 13.9 & 49.1 & 45.8 \\
\hline 4 & 8 & 7.4 & 30.5 & 30.2 \\
\hline 5 & 37.5 & 31.8 & 52.2 & 51 \\
\hline 6 & 29.8 & 22.6 & 29.5 & 25.1 \\
\hline 7 & 31.2 & 27.5 & 39.5 & 31.1 \\
\hline 8 & 17.3 & 15.9 & 19.6 & 17.1 \\
\hline 9 & 87.1 & 84.8 & 95.4 & 113.4 \\
\hline 10 & 51.9 & 49.5 & 52.7 & 46.7 \\
\hline Mean $\pm \sigma$ & $31.3 \pm 23.5$ & $28.0 \pm 23.4$ & $41.3 \pm 22.9$ & $39.7 \pm 28.8$ \\
\hline
\end{tabular}


LAD and LCx, so that retrograde flow is lower. Some situations of retrograde flow have been reported previously in the literature: for example, in arterial conduits grafted to coronary arteries with lower grade stenosis [9, $11,12]$. However, the situation studied in this paper is somewhat different because of the LMCA stenosis.

This observation about Patient 9 is consistent with the high flow rates predicted in its LCx branch (this patient has no stenosis on $\mathrm{LCx}$ and a low $\mathrm{R}_{\mathrm{LCx}}$ value). Patient 10 has also no stenosis on LCx, but he does not present such a disproportion between $\mathrm{R}_{\mathrm{LCxc}}$ and $\mathrm{R}_{\mathrm{LADc}}$.

This demonstrates that the values of the capillary and collateral resistances have a major impact on all the pressures and flow rates, including the flow rates in the grafts. For example, an elevated value of $\mathrm{Q}_{\mathrm{LADg}}$ is obtained for Patient 4 because $R_{\text {LADc }}$ is specially low for this patient (on the contrary, Patient 4 has severe stenosis on $\mathrm{LCx}$; consequently, low $\mathrm{Q}_{\mathrm{LCx}}$ flow rates are predicted for this patient in the case $0 \mathrm{G}$ and $1 \mathrm{G}$ ). Patients who have rather high values of $\mathrm{R}_{\mathrm{LCxc}}$ have rather low flow rates in the LCx graft (for example, Patients 1, 2, 6, 8). Conversely, patients who have rather low values of $\mathrm{R}_{\mathrm{LCxc}}$ have rather large flow rates in the LCx graft (for example, Patients 3, 5, 9). Such a correlation between graft flow and grafted perfusion area has been demonstrated previously by Hirotani et al. [13].

As we previously found in [14], a small decrease (a few $\mathrm{ml} / \mathrm{min}$ ) of the flow rates in the left grafts can be noticed in the case (3G) compared to the case $(2 \mathrm{G})$.

\subsection{Flows and Pressures in the RCA Branch}

The values of the pressures distal to the thrombosis on $\operatorname{RCA}\left(\mathrm{P}_{\mathrm{w}}\right)$, of the flow rates in the RCA graft $\left(\mathrm{Q}_{\mathrm{RCAg}}\right)$, and of the flow rates in the right capillary area $\left(\mathrm{Q}_{\mathrm{RCAc}}\right)$ are presented in Table 6.

As we previously found in [2], no significant change in the mean value of $\mathrm{P}_{\mathrm{w}}$ in the presence of the left grafts (case $(2 \mathrm{G})$ compared to case $(0 \mathrm{G})$ ) can be demonstrated. Moreover, no evident correlation appears between the values of $\mathrm{P}_{\mathrm{w}}$ and the corresponding flow rates in the right capillary area, $\mathrm{Q}_{\mathrm{RCAc}}$.

The flow rates $Q_{R C A g}(1 G)$ are slightly higher than $\mathrm{Q}_{\mathrm{RCAg}}(3 \mathrm{G})$ (mean value of $\mathrm{Q}_{\mathrm{RCAg}}$ in the case $(1 \mathrm{G})=51.5$ \pm 27.6 and in the case $(3 \mathrm{G})=44.7 \pm 23.2)$ because of the negative collateral flows that exist in the case (1G) (For example, for Patient1, because of the severe obstruction of the LAD artery, $\mathrm{Q}_{\mathrm{col} 4}$ is important $(=-15 \mathrm{ml} / \mathrm{min}$, see Table 7)).

For all patients, the perfusion of the right territory, $\mathrm{Q}_{\mathrm{RCAc}}$, is improved in the presence of the right graft (mean value of $Q_{R C A c}$ in the case $(1 G)=44.7 \pm 23.5$, and in the case $(3 \mathrm{G})=43.6 \pm 22.8$; mean value of $\mathrm{Q}_{\mathrm{RCAc}}$ in the case $(0 \mathrm{G})=19.3 \pm 10.3$, and in the case $(2 \mathrm{G})=20.5 \pm$
Table 6. Values of the pressures distal to the thrombosis on RCA $\left(\mathrm{P}_{\mathrm{w}}\right.$, in $\left.\mathrm{mmHg}\right)$, of the flow rates $(\mathrm{ml} / \mathrm{min})$ in the RCA graft $\left(\mathrm{Q}_{\mathrm{RCAg}}\right)$, and in the right capillary area $\left(\mathrm{Q}_{\mathrm{RCAc}}\right)$.

\begin{tabular}{|c|c|c|c|c|}
\hline Patient & $\mathrm{P}_{\mathrm{w}} \mathrm{Cli}(0 \mathrm{G})$ & $\mathrm{P}_{\mathrm{w}}(0 \mathrm{G})$ & $\mathrm{P}_{\mathrm{w}} \mathrm{Cli}(2 \mathrm{G})$ & $\mathrm{P}_{\mathrm{w}}(2 \mathrm{G})$ \\
\hline 1 & 35 & 31.6 & 31 & 31.3 \\
\hline 2 & 49 & 44.5 & 49 & 49 \\
\hline 3 & 40 & 33.1 & 40 & 40.1 \\
\hline 4 & 43 & 38.3 & 42 & 42.3 \\
\hline 5 & 53 & 41.4 & 36 & 35.7 \\
\hline 6 & 35 & 28.2 & 28 & 28.4 \\
\hline 7 & 29 & 37 & 40 & 40.2 \\
\hline 8 & 46 & 45.1 & 43 & 44.5 \\
\hline 9 & 37 & 37.9 & 40 & 40 \\
\hline 10 & 47 & 44.9 & 48 & 48.2 \\
\hline Mean $\pm \sigma$ & $41.4 \pm 7.5$ & $38.2 \pm 5.9$ & $39.7 \pm 6.6$ & $40.0 \pm 6.7$ \\
\hline Patient & $\mathrm{Q}_{\mathrm{RCAg}}(1 \mathrm{G})$ & $\mathrm{Q}_{\mathrm{RCAg}} \mathrm{Cli}(3 \mathrm{G})$ & $\mathrm{Q}_{\mathrm{RCAg}}(3 \mathrm{G})$ & \\
\hline 1 & 88.2 & 66 & 67.6 & \\
\hline 2 & 52.4 & 45 & 45.4 & \\
\hline 3 & 86.6 & 74 & 75.3 & \\
\hline 4 & 35.1 & 26 & 27 & \\
\hline 5 & 85.4 & 69 & 70.5 & \\
\hline 6 & 31.9 & 30 & 30.3 & \\
\hline 7 & 55.9 & 51 & 52 & \\
\hline 8 & 14.6 & 10 & 10.5 & \\
\hline 9 & 45.6 & 51 & 53.2 & \\
\hline 10 & 18.9 & 14 & 14.8 & \\
\hline Mean $\pm \sigma$ & $51.5 \pm 27.6$ & $43.6 \pm 22.8$ & $44.7 \pm 23.2$ & \\
\hline Patient & $\mathrm{Q}_{\mathrm{RCAc}}(0 \mathrm{G})$ & $\mathrm{Q}_{\mathrm{RCAc}}(1 \mathrm{G})$ & $\mathrm{Q}_{\mathrm{RCAc}}(2 \mathrm{G})$ & $\mathrm{Q}_{\mathrm{RCAc}}(3 \mathrm{G})$ \\
\hline 1 & 31.5 & 70.3 & 34.6 & 66 \\
\hline 2 & 21.9 & 47.4 & 22.3 & 45 \\
\hline 3 & 25.8 & 73.9 & 31.6 & 74 \\
\hline 4 & 11.9 & 28 & 13.2 & 26 \\
\hline 5 & 38.8 & 75.3 & 34.9 & 68.9 \\
\hline 6 & 11.3 & 30 & 11.4 & 30 \\
\hline 7 & 18.1 & 53.4 & 20.7 & 51 \\
\hline 8 & 6.7 & 12.1 & 6.6 & 10 \\
\hline 9 & 17.7 & 41.4 & 19.3 & 51 \\
\hline 10 & 9.8 & 15.1 & 10.7 & 14 \\
\hline Mean $\pm \sigma$ & $19.3 \pm 10.3$ & $44.7 \pm 23.5$ & $20.5 \pm 10.3$ & $43.6 \pm 22.8$ \\
\hline
\end{tabular}


Table 7. Values of the collateral flow rates $(\mathrm{ml} / \mathrm{min})$, for each patient, in the four different revascularization situations.

\begin{tabular}{|c|c|c|c|c|}
\hline Patient & $\mathrm{Q}_{\text {col1 }}(0 \mathrm{G})$ & $\mathrm{Q}_{\text {col1 }}(1 \mathrm{G})$ & $\mathrm{Q}_{\text {col1 }}(2 \mathrm{G})$ & $\mathrm{Q}_{\text {col1 }}(3 \mathrm{G})$ \\
\hline 1 & 10.6 & 0.1 & 7.4 & 0.1 \\
\hline 2 & 5.6 & 0 & 4.6 & 0.1 \\
\hline 3 & 6.2 & -1.4 & 6.2 & -0.1 \\
\hline 4 & 3.9 & 0 & 2.8 & 0 \\
\hline 5 & 10.4 & 0.1 & 7.4 & 0.1 \\
\hline 6 & 2.5 & -0.2 & 2.3 & 0 \\
\hline 7 & 3.6 & -0.5 & 4.1 & -0.2 \\
\hline 8 & 1.4 & -0.4 & 1.3 & -0.1 \\
\hline 9 & 3.4 & -1 & 3.7 & -0.6 \\
\hline 10 & 2.5 & -0.3 & 2.1 & -0.1 \\
\hline Mean $\pm \sigma$ & $5.0 \pm 3.2$ & $-0.4 \pm 0.5$ & $4.2 \pm 2.2$ & $-0.1 \pm 0.2$ \\
\hline Patient & $\mathrm{Q}_{\mathrm{col3} 3}(0 \mathrm{G})$ & $\mathrm{Q}_{\mathrm{col3} 3}(1 \mathrm{G})$ & $\mathrm{Q}_{\mathrm{col} 3}(2 \mathrm{G})$ & $\mathrm{Q}_{\mathrm{col} 3}(3 \mathrm{G})$ \\
\hline 1 & 10.7 & 0.1 & 7.4 & 0.1 \\
\hline 2 & 5.7 & 0.1 & 4.6 & 0.1 \\
\hline 3 & 8.9 & 0.1 & 6.9 & 0.1 \\
\hline 4 & 3.9 & 0.1 & 2.8 & 0 \\
\hline 5 & 10.5 & 0.1 & 7.4 & 0.1 \\
\hline 6 & 2.8 & 0 & 2.4 & 0 \\
\hline 7 & 4.3 & 0.1 & 4.4 & 0.1 \\
\hline 8 & 1.9 & 0 & 1.5 & 0 \\
\hline 9 & 4.6 & 0.1 & 4.3 & 0.1 \\
\hline 10 & 2.8 & 0 & 2.4 & 0 \\
\hline Mean $\pm \sigma$ & $5.6 \pm 3.3$ & $0.1 \pm 0.1$ & $4.4 \pm 2.2$ & $0.1 \pm 0.1$ \\
\hline Patient & $\mathrm{Q}_{\mathrm{col} 4}(0 \mathrm{G})$ & $\mathrm{Q}_{\mathrm{col} 4}(1 \mathrm{G})$ & $\mathrm{Q}_{\mathrm{col} 4}(2 \mathrm{G})$ & $\mathrm{Q}_{\mathrm{col} 4}(3 \mathrm{G})$ \\
\hline 1 & -7.0 & -15.6 & 5.8 & -1.4 \\
\hline 2 & 3.3 & -1.9 & 4.2 & -0.3 \\
\hline 3 & 4.9 & -2.4 & 6.3 & -0.3 \\
\hline 4 & 1.5 & -2.4 & 2.2 & -0.7 \\
\hline 5 & 6.2 & -2.8 & 6.7 & -0.4 \\
\hline 6 & 1.1 & -1.2 & 2.3 & -0.1 \\
\hline 7 & 3.6 & -0.5 & 4.0 & -0.3 \\
\hline 8 & 1.2 & -0.7 & 1.2 & -0.2 \\
\hline 9 & 3.1 & -1.16 & 3.9 & -0.3 \\
\hline 10 & -0.4 & -2.8 & 2.0 & -0.3 \\
\hline Mean $\pm \sigma$ & $1.7 \pm 3.6$ & $-3.1 \pm 4.4$ & $3.9 \pm 1.9$ & $-0.4 \pm 0.4$ \\
\hline
\end{tabular}

\begin{tabular}{ccccc}
\hline Patient & $\mathrm{Q}_{\text {col5 }}(0 \mathrm{G})$ & $\mathrm{Q}_{\text {col5 }}(1 \mathrm{G})$ & $\mathrm{Q}_{\text {col5 }}(2 \mathrm{G})$ & $\mathrm{Q}_{\mathrm{col} 5}(3 \mathrm{G})$ \\
\hline 1 & 6.6 & -2.6 & 6.7 & -0.4 \\
2 & 1.8 & -3.1 & 4.3 & -0.2 \\
3 & -0.4 & -7.5 & 5.9 & -0.8 \\
4 & -1.2 & -4.7 & 2.5 & -0.3 \\
5 & 1.5 & -7.4 & 5.9 & -1.3 \\
6 & 2.3 & -0.4 & 2.2 & -0.1 \\
7 & 3.0 & -1.0 & 4.0 & -0.3 \\
8 & 0.9 & -0.9 & 1.3 & -0.1 \\
9 & 3.3 & -1.0 & 3.7 & -0.7 \\
10 & 2.4 & -0.3 & 2.1 & -0.2 \\
Mean $\pm \sigma$ & $2.0 \pm 2.1$ & $-2.9 \pm 2.8$ & $3.9 \pm 1.8$ & $-0.4 \pm 0.4$ \\
\hline
\end{tabular}

10.3). However, for patients 8 and 10, this perfusion appears to be critically low. This seems to be related to their high values of the right capillary resistance $\mathrm{R}_{\mathrm{RCAc}}$. For patients 4 and $6, \mathrm{Q}_{\mathrm{RCAc}}$ is low in the case $(0 \mathrm{G})$ and $(2 \mathrm{G})$, and this seems to be related to high values of the collateral resistance $\mathrm{R}_{\mathrm{col}}$.

For patients 7, 9 and 10, the important $\mathrm{Q}_{\mathrm{LAD1}}$ or $\mathrm{Q}_{\mathrm{LCx} 1}$ flow rates due to the absence of stenoses on the LAD or LCx branch are not associated with any particular improvement of the right territory perfusion.

More generally, it appears from the results of Table 6, that, in the presence of the left grafts, the $\mathrm{Q}_{\mathrm{RCAc}}$ flow rates are not significantly modified (mean value of $\mathrm{Q}_{\mathrm{RCAc}}$ in the case $(2 \mathrm{G})=20.5 \pm 10.3$, and mean value of $\mathrm{Q}_{\mathrm{RCAc}}$ in the case $(0 \mathrm{G})=19.3 \pm 10.3)$. Most of the blood brought by the left grafts is used to perfuse the distal left territories $\left(\mathrm{Q}_{\mathrm{LADc}}\right.$ and $\left.\mathrm{Q}_{\mathrm{LCxc}}\right)$. This observation is consistent with our previous results $[1,15]$.

\subsection{Collateral Flows}

The results of the collateral flows are presented in Table 7, for each patient and each revascularization situation. Because of the assumption that the collateral resistances are the same (Eq.4), we have $\mathrm{P}_{\mathrm{M}}-\mathrm{P}_{\mathrm{w}}=\mathrm{R}_{\text {col }}$. $\mathrm{Q}_{\text {col1 }}=\mathrm{R}_{\text {col }}$. $\mathrm{Q}_{\text {col2 }}$ (see Figure 2); consequently, $\mathrm{Q}_{\mathrm{col1}}=\mathrm{Q}_{\mathrm{col} 2}$.

In the situation $(0 G)$ and $(2 G)$, the flow is delivered to the right territory via the collaterals only. However, it can be seen from Table 7 that these collateral flows remain low in all cases. The presence of the left grafts does not really improve the collateral flows. In the case of Patient1, we obtain a negative $\mathrm{Q}_{\text {col4 }}$ value in the pathological situation $(0 \mathrm{G})$. This indicates that blood flows from the right artery to the LAD, which is almost totally occluded. The same remark can be made for $\mathrm{Pa}$ tients 3 and 4, whose collateral flow rates $\mathrm{Q}_{\text {cols }}(0 \mathrm{G})$ are 
negative because severe stenoses are present on the LCx artery.

Such reverse collateral flow also exists when the right graft is present, especially in the case $(1 \mathrm{G})$ : due to the presence of the right graft, the right territory is better perfused and the pressures in the right area become higher than those of the left territories. This has been also demonstrated by other authors: Miyamoto et al. [16] have shown that revascularization of the receiving artery can reverse the pressure gradient across the collateral network, establishing collateral flow in the opposite direction.

$\mathrm{Q}_{\text {col1 }}$ and $\mathrm{Q}_{\mathrm{col} 2}$, in the case $0 \mathrm{G}$, are slightly higher than $\mathrm{Q}_{\text {col1 }}$ and $\mathrm{Q}_{\text {col2 }}$, in the case $2 \mathrm{G}$ (mean value of $\mathrm{Q}_{\text {col1 }}$ in the case $(0 \mathrm{G})=5.0 \pm 3.2$, and in the case $(2 \mathrm{G})=4.2 \pm 2.2)$. This is consistent with the fact that, in the presence of the left grafts, the flow in the native artery decreases, and consequently, $\mathrm{Q}_{\mathrm{col} 11}$ and $\mathrm{Q}_{\mathrm{col} 2}$ decrease.

For patients with moderate lesions on LMCA and severe stenoses on LAD and LCx (for example, patient 1 and 5), the blood is forced to flow through $\mathrm{R}_{\text {col1 }}$ and $\mathrm{R}_{\text {col2 }}$, yielding values of $Q_{\text {col1 }}$ and $Q_{\text {col2 }}$ in the case $(0 \mathrm{G})$ higher than those obtained for other patients. For these patients, $\mathrm{Q}_{\text {col3 }}$ is high also, because $\mathrm{R}_{\text {col }}$ is low. For the same reason, the collateral flows of the case $(2 \mathrm{G})$ for these patients are somewhat higher than those obtained for other patients.

We also notice that, in the case $(0 \mathrm{G})$ and $(2 \mathrm{G}), \mathrm{Q}_{\mathrm{col} 3}$ directly varies as the pressure $\operatorname{drop}\left(\mathrm{P}_{\mathrm{ao}}-\mathrm{P}_{\mathrm{w}}\right)$.

In the case $(3 \mathrm{G})$, the collateral flows become negligible. Loss of collateral flow after revascularization agrees with the findings of previous studies: Wang et al. found that collateral flow disappeared in $12 / 14$ patients after grafting of the RCA [17]. Werner et al. also demonstrated regression of collateral function after recanalization of chronic total coronary occlusions [18].

\subsection{Total Flow Qt}

The results obtained for $\mathrm{Q}_{\mathrm{t}}$ are shown in Table 8. It appears that the better perfusion will be obtained with the three grafts. In the case $(2 \mathrm{G})$, there is an improvement of $\mathrm{Q}_{\mathrm{t}}$, compared to the pathological case $(0 \mathrm{G})$ (mean value of $\mathrm{Q}_{\mathrm{t}}$ in the $(2 \mathrm{G})$ case $=91.4 \pm 26.4$, and in the $(0 \mathrm{G})$ case $=$ $75.3 \pm 24.7)$, but this improvement is related to an increase of $\mathrm{Q}_{\mathrm{LAD}}$ and $\mathrm{Q}_{\mathrm{LCx}}$, and the presence of the left grafts does not really improve $\mathrm{Q}_{\mathrm{RCAc}}$. Conversely, in the case (1G), $\mathrm{Q}_{\mathrm{RCAc}}$ is improved by the presence of the right graft, but $\mathrm{Q}_{\mathrm{LAD}}$ and $\mathrm{Q}_{\mathrm{LCx}}$ remain rather the same as in the pathological case. This demonstrates that, for the patients considered in this study, complete revascularization (with the 3 grafts) is fully justified. However, for Patient 8 and 10 (and in a lesser extent, 6), the revascularization yields a very small improvement of $Q_{t}$.
Table 8. Values of the total flow rates $Q_{t}(\mathrm{ml} / \mathrm{min})$, for each patient, in the four different revascularization situations.

\begin{tabular}{ccccc}
\hline Patient & $\mathrm{Q}_{\mathrm{t}}(0 \mathrm{G})$ & $\mathrm{Q}_{\mathrm{t}}(1 \mathrm{G})$ & $\mathrm{Q}_{\mathrm{t}}(2 \mathrm{G})$ & $\mathrm{Q}_{\mathrm{t}}(3 \mathrm{G})$ \\
\hline 1 & 51.9 & 102.2 & 82.3 & 122.9 \\
2 & 55.9 & 84.5 & 64.1 & 89.4 \\
3 & 57.1 & 113.3 & 94.5 & 141.9 \\
4 & 75.8 & 98.7 & 108.1 & 129.4 \\
5 & 94.5 & 135.3 & 100.2 & 142.8 \\
6 & 49.3 & 62.5 & 54.2 & 69.6 \\
7 & 120.2 & 155.6 & 139.9 & 156.4 \\
8 & 67.7 & 74.2 & 70.2 & 69.7 \\
9 & 108.8 & 134.9 & 119.6 & 175.7 \\
10 & 71.7 & 78.5 & 81.2 & 79.4 \\
Mean $\pm \sigma$ & $75.3 \pm 24.7$ & $104 \pm 30.5$ & $91.4 \pm 26.4$ & $117.7 \pm 38.2$ \\
\hline
\end{tabular}

\section{DISCUSSION}

To the best of our knowledge, the current study is unique because of the specific three vessel disease situation, and because our simulations take into account simultaneously the effect of revascularization, the grade of native arteries stenoses and the collaterality.

The values presented in this paper for the flow rates, pressures, capillary and collateral resistances, are in complete agreement with the results previously obtained with a less sophisticated version of the model [1]. The range of these values and the main assumptions and limitations of the model have already been discussed in [1].

In spite of these limitations, the clinical relevance of our results seem good; the results confirm the surgeons professional experience and agree with the data and analysis that can be found in the literature.

The most important features shown by the calculations can be summarized as follows:

- Important variability between individuals for their capillary resistances and collateral resistances $\left(\mathrm{R}_{\mathrm{LADc}}, \mathrm{R}_{\mathrm{LCxc}}, \mathrm{R}_{\mathrm{RCAc}}, \mathrm{R}_{\mathrm{col}}\right)$. This supports the motivation of our work to develop patient's specific simulations.

- The complete revascularization is fully justified for these patients because neither the right graft alone, nor the left grafts alone can ensure a sufficient perfusion improvement for the heart. The left grafts mainly contribute to a better perfusion of the left territories, instead of the collateralized right region. In all cases, the contribution of the collateral flows remain low (a few $\mathrm{ml} / \mathrm{min}$ ). 
- When the three grafts are functional, the collateral channels play no more role and a severe reduction of the flow rates in the native left arteries is demonstrated (depending on their degree of occlusion). The left grafts could thus promote progression of the native disease.

- The values of the capillary resistances and collateral resistances have a major impact on the flows and pressures everywhere in the network and it appears that each variable depends on all the others. For example, it is difficult to study separately the influence of the LAD stenosis or LCx stenosis, because the flow in the corresponding branch also depends on the LMCA stenosis, on the capillary resistance $R_{L A D c}$ or $R_{L C x c}$, on the collateral resistance $\mathrm{R}_{\text {col }}$, on the pressure difference between the left and right branches, on the aortic and venous pressures, ...

However, further work is necessary to improve the physiological relevance of the present model:

- Improve the representation of collateral vessels (the assumption that all the collateral resistances are the same is probably not very realistic)

- Take into account the capillary resistance variation during the cardiac cycle, due to myocardial contraction

In a further step, the model could then be transformed in order to work with pre-operative clinical measurements and thus become a full predictive model.

\section{REFERENCES}

[1] Maasrani, M., Verhoye, J.P., Corbineau, H. and Drochon, A. (2008) Analog electrical model of the coronary circulation in case of multiple revascularizations. Annals Biomedical Engineering, 36, 1163-1174. doi:10.1007/s10439-008-9500-5

[2] Verhoye J. Ph., De Latour B., Drochon A. and Corbineau H. (2005) Collateral flow reserve and right coronary occlusion: evaluation during off-pump revascularization. Interactive Cardiovascular Thoracic Surgery, 4, 23-26. doi:10.1510/icvts.2004.093088

[3] Olufsen, M. and Nadim, A. (2004) On deriving lumped models for blood flow and pressure in the systemic arteries. Math Biosciences Engineering, 1, 61-80.

[4] Pietrabissa, R., Mantero, S., Marotta, T. and Menicanti, L. (1996) A lumped parameter model to evaluate the fluid dynamics of different coronary bypasses. Medical Engineering \& Physics, 18, 477-484. doi:10.1016/1350-4533(96)00002-1

[5] Wang, J.Z., Tie, B., Welkowitz, W., Kostis, J. and Semmlow, J. (1989) Incremental network analogue model of the coronary artery. Medical \& Biological Engineering \& Computing., 27, 416-422. doi:10.1007/BF02441434

[6] Maasrani, M., Abouliatim, I., Ruggieri, V.G., Corbineau, H., Verhoye, J.P. and Drochon, A. (2010) Simulations of fluxes in diseased coronary network using an electrical model. Proceedings of the XIX International Conference on Electrical Machines, IEEE -ICEM 2010, Rome.

[7] Shimizu, T., Hirayama, T., Suesada, H., Ikeda, K., Ito, S. and Ishimaru, S. (2000) Effect of flow competition on internal thoracic artery graft: postoperative velocimetric and angiographic study. Journal of Thoracic and Cardiovascular Surgery, 120, 459-465.

doi: $10.1067 / \mathrm{mtc} .2000 .108166$

[8] Lust, R., Zeri, R., Spence, P., Hopson, S., Sun, Y., Otaki, M., Jolly, S., Mehta, P. and Chitwood, W. (1994) Effect of chronic native flow competition on internal thoracic artery grafts. Annals of Thoracic Surgery, 57, 45-50. doi:10.1016/0003-4975(94)90363-8

[9] Kawasuji, M., Sakakibara, N., Takemura, H., Tedoriya, T., Ushijima, T. and Watanabe, Y. (1996) Is internal thoracic artery grafting suitable for a moderately stenotic coronary artery? Journal of Thoracic and Cardiovascular Surgery, 112, 253- 259. doi:10.1016/S0022-5223(96)70246-5

[10] Berger, A., Mac Carthy, P., Siebert, U., Carlier, S., Wijns, W., Heyndrickx, G., Bartunek, J., Vanermen, H. and De Bruyne, B. (2004) Long-term patency of internal mammary artery bypass grafts; relationship with preoperative severity of the native coronary artery stenosis. Circulation, 110, II36-II40. doi:10.1161/01.CIR.0000141256.05740.69

[11] Berger A., Mac Carthy P., Vanermen H. and De Bruyne B. (2004) Occlusion of internal mammary grafts: a review of the potential causative factors. Acta Chirurgica Belgica, 104, 630-634.

[12] Shimizu, T., Ito, S., Kikuchi, Y., Misaka, M., Hirayama, T., Ishimaru, S. and Yamashina, A. (2004) Arterial conduit shear stress following bypass grafting for intermediate coronary artery stenosis: A comparative study with saphenous vein grafts. European Journal of CardioThoracic Surgery, 25, 578-584. doi:10.1016/i.ejcts.2003.12.039

[13] Hirotani, T., Kameda, T., Shirota, S., and Nakao, Y. (2001) An evaluation of the intraoperative transit time measurements of coronary bypass flow. European Journal of Cardio-Thoracic Surgery, 19, 848-852. doi:10.1016/S1010-7940(01)00700-X

[14] Verhoye, J. P., Abouliatim, I., Drochon, A., De Latour, B., Leclercq, C., Leguerrier, A. and Corbineau, H. (2007) Collateral blood flow between left coronary artery bypass grafts and chronically occluded right coronary circulation in patients with triple-vessel disease. European Journal of Cardio-Thoracic Surgery, 31, 49-54. doi:10.1016/i.ejcts.2006.09.033

[15] Maasrani, M., Drochon, A., Abouliatim, I., Corbineau, H. and Verhoye, J.P. (2010) Theoretical simulations of the influence of the stenoses severity and revascularization status on the right territory perfusion in case of severe coronary disease and occlusion of the right artery. Computer Methods in Biomechanics and Biomedical Engineering, 13, 93-94. doi:10.1080/10255842.2010.494037

[16] Miyamoto, S., Fujita, M., and Sasayama, S. (2000) Bidirectional function of coronary collateral channels in humans. International Journal of Cardiology, 75, 249-252. doi:10.1016/S0167-5273(00)00313-2 
[17] Wang, J., Filipovic, M., Skarvan, K., Michaux, I., Schumann, R., Buser, P. and Seeberger, M. (2006) Transeosophageal Doppler echocardiographic detection of intramyocardial collateral flow to the right coronary artery and changes in the flow to the left inferior ventricular wall immediately after coronary bypass grafting. American Journal of Cardiology, 98, 1587-1592. doi:10.1016/j.amjcard.2006.07.034

[18] Werner G., Emig U., Mutschke O., Schwarz G., Bahrmann P., and Figulla H. (2003) Regression of collateral function after recanalization of chronic total coronary occlusions. A serial assessment by intracoronary pressure and Doppler recordings. Circulation, 108, 2877-2882. doi:10.1161/01.CIR.0000100724.44398.01 


\section{NOMENCLATURE}

LMCA: left main coronary artery

LAD: left anterior descending artery

LCx: left circumflex branch

$\mathrm{RCA}$ : right coronary artery

$\mathrm{P}_{\mathrm{ao}}$ : aortic pressure

$\mathrm{P}_{\mathrm{v}}$ : central venous pressure

$\mathrm{P}_{\mathrm{w}}$ : pressure distal to the RCA occlusion

$\mathrm{R}_{\mathrm{LADc}}$ : resistances of the capillaries vascularized by the LAD artery

$\mathrm{R}_{\mathrm{LCXc}}$ : resistances of the capillaries vascularized by the LCx artery

$\mathrm{R}_{\mathrm{RCAc}}$ : resistances of the capillaries vascularized by the RCA artery

$\mathrm{Q}_{\mathrm{RCAg}}$ : flow rate in the RCA graft

$\mathrm{Q}_{\mathrm{LADg}}$ : flow rate in the LAD graft

$\mathrm{Q}_{\mathrm{LCxg}}$ : flow rate in the LCx graft

$\mathrm{Q}_{\mathrm{LAD1}}$ : flow rate in the native stenosed LAD
$\mathrm{Q}_{\mathrm{LCx} 1}$ : flow rate in the native stenosed $\mathrm{LCx}$

$\mathrm{Q}_{\mathrm{LADc}}$ : blood flow rate across the LAD capillaries

$\mathrm{Q}_{\mathrm{LCX}}$ : blood flow rate across the LCX capillaries

$\mathrm{Q}_{\mathrm{RCAc}}$ : blood flow rate across the RCA capillaries

$\mathrm{Q}_{\text {col1 }}$ : collateral flow rate from LAD towards RCA before

LAD stenosis

$\mathrm{Q}_{\text {col14}}$ : collateral flow rate from LAD towards RCA after LAD stenosis

$\mathrm{Q}_{\text {col2 }}$ : collateral flow rate from $\mathrm{LC}_{\mathrm{X}}$ before $\mathrm{LCX}$ stenosis

$\mathrm{Q}_{\text {col5 }}$ : collateral flow rate from $\mathrm{LC}_{\mathrm{X}}$ after $\mathrm{LC}_{\mathrm{X}}$ stenosis

$\mathrm{Q}_{\mathrm{col} 3}$ : collateral flow rate from the aorta towards the RCA

$\mathrm{R}$ : resistance

C: capacitance

$\mathrm{L}$ : inductance

IMAG: internal mammary artery graft

SVG: saphenous vein graft

ITA: internal thoracic artery 